\title{
Umidade e água disponível no solo em monocultivo de pastagem e sistema silvipastoril com fileiras duplas de eucalipto
}

\author{
Erni Limberger ${ }^{1}$, Jonez Fidalski ${ }^{1}$, Wander de Souza ${ }^{1}$, Marcio Antonio Baliscei ${ }^{1}$, Juliano Carlos Calonego ${ }^{2}$ \\ ${ }^{1}$ Instituto de Desenvolvimento Rural do Paraná - IAPAR-EMATER (IDR-Paraná), PR. ${ }^{2}$ Universidade Estadual Paulista - \\ UNESP, Faculdade de Ciências Agronômicas, Botucatu, SP. E-mail: ernilimberger@idr.pr.gov.br
}

\begin{abstract}
Resumo
A expansão de sistema silvipastoril poderia ser realizada por meio da reforma do sistema de monocultivo de pastagem, em solo com a camada superficial arenosa, mas os agropecuaristas receiam que possa haver competição pela água no solo entre a pastagem e o eucalipto. O objetivo deste trabalho foi avaliar a umidade e a água disponível em sistema silvipastoril e monocultivo de pastagem em diferentes estações do ano, distância dos troncos de eucaliptos ou dos terraços a $1 \mathrm{~m}$ de profundidade em um Latossolo Vermelho Distrófico típico. A reforma de pastagem foi realizada em 12 ha com o cultivo de mandioca (2008-2010), tendo sido as mudas de eucalipto plantadas simultaneamente ao plantio das manivas de mandioca em agosto de 2008. Avaliaram-se dois sistemas entre terraços espaçados em $20 \mathrm{~m}$ : a) sistema de monocultivo de pastagem grama-estrela roxa (Cynodon nlemfuensis) e b) sistema silvipastoril (2x3)+20 com gramaestrela roxa e eucalipto (Eucalyptus grandis). 0 conteúdo de água no solo $(\theta)$ foi determinado nas quatro estações do ano para eucaliptos com 2 a 3 anos de idade, entre julho/2010 a março/2011. Utilizaram-se as seguintes posições de amostragem: 2,5, 5 e $10 \mathrm{~m}$ da linha de plantio do eucalipto a jusante dos terraços. Amostras deformadas de solo foram coletadas a 0-0,2 $\mathrm{m}$ (horizonte $\mathrm{A}$ - areia-franca), 0,2-0,4 (horizonte Bw1 - franco-arenosa), e 0,4-0,6, 0,6-0,8 e 0,8-1,0 m (horizonte Bw2 - franco-argilo-arenosa). Determinaram-se $\theta$ na capacidade de campo e ponto de murcha permanente. $O$ sistema silvipastoril comparado ao monocultivo de pastagem diminuiu $\theta$ no horizonte Bw2. $0 \theta$ esteve dentro dos limites da água disponível nos horizontes A e Bw1 para a grama-estrela roxa entre as fileiras duplas de eucalipto no sistema silvipastoril durante as estações do ano. $O$ sistema silvipastoril implantado não compromete o $\theta$ para a grama-estrela roxa a 0-0,4 m de profundidade.

Palavras-chave: água no solo; integração lavoura-pecuária-floresta; reforma de pastagem; textura do solo.
\end{abstract}

Moisture and water available in soil in forage grass monoculture and silvipastoral system with doubles rows of eucalyptus

\begin{abstract}
The expansion of silvipastoral system could be achieved through reform of forage grass monoculture system in soil with a sandy surface layer, but ranchers are concerned that there may be competition for soil water between the pasture and eucalyptus. The objective of this study was to evaluate the moisture and water available in silvipastoral system and forage grass monoculture in different seasons, distance of eucalyptus trunks or terraces at $1 \mathrm{~m}$ depth in a Hapludox soil. Reclamation forage grass monoculture was held with cassava (2008-2010), being the eucalyptus seedlings planted simultaneously to the planting of cassava in August 2008. Two systems of terraces spaced $20 \mathrm{~m}$ were evaluated: a) forage grass monoculture stargrass (Cynodon nlemfuensis) system and b) silvipastoral system $(2 \times 3)+20$ with stargrass forage and eucalypt tree (Eucalyptus grandis). The soil water content $(\theta)$ was determined in four seasons for eucalyptus tree had 2-3-year-old, from July/2010 to March/2011. Use the following sampling positions: 2.5, 5 and $10 \mathrm{~m}$ away from the rows of eucalyptus trees downstream of the terraces. Disturbed soil samples were collected at 0-0.2 m (A horizon - sandy texture), 0.2-0.4 (Bw1 - sandy loam texture), and 0.4-0.6, 0.60.8 and $0.8-1.0 \mathrm{~m}$ (Bw2 - sandy clay cloam). Field capacity and permanent wilting point waters contents was determined. The silvipastoral system compared to forage grass monoculture system decreases $\theta$ on
\end{abstract}


the horizon Bw2. The $\theta$ was within the limits of the water available in the horizons A and Bw1 for the stargrass forage between the double rows of eucalyptus trees in silvipastoral system during the seasons. The silvipastoral system implemented does not compromise $\theta$ to stargrass forage at 0-0.4 m depth.

Keywords: soil water; crop-livestock-forest integration; reclamation grassland; soil texture.

\section{Introdução}

Os agropecuaristas receiam que 0 eucalipto possa diminuir a umidade no solo, na camada superficial com textura arenosa, comum em unidades litoestratigráficas do Alogrupo Rio Paraná, que ocorrem nos estados do Paraná, Mato Grosso do Sul e São Paulo (SALLUN et al., 2007), perfazendo $200.000 \mathrm{~km}^{2}$ (SALLUN et al., 2008), com baixa retenção e disponibilidade de água (FIDALSKI et al., 2013). Nestes Estados, os sistemas silvipastoris poderiam ser implantados durante a reforma de pastagens degradadas com o cultivo de mandioca (MARUN; MELLA, 1997; NEPOMUCENO; SILVA, 2009). O Brasil havia reflorestado até 2012 cerca de 5 milhões de hectares, dos quais $71 \%$ com Eucalyptus spp. (COLODETTE et al., 2014), e o conhecimento científico para a implantação de sistemas silvipastoris no Brasil poderia ampliar a expansão deste sistema (FEY et al., 2015).

O sistema silvipastoril está baseado no plantio de espécies florestais, principalmente com eucalipto, formando renques em nível com uma a três fileiras de eucalipto entre faixas de pastagem de 10 a $42 \mathrm{~m}$ (NEPOMUCENO; SILVA, 2009; BALISCEI et al., 2012; ZAMBRANO, 2013; FRANCHINI et al., 2014; PEZZOPANE et al., 2015), principalmente com Urochloa brizantha, Megathyrsus maximum e grama-estrela (C. nlemfuensis) (NEPOMUCENO; SILVA, 2009). O espaçamento entre as fileiras duplas de eucalipto é muito importante no planejamento do sistema silvipastoril, porque a produtividade da pastagem intercalar ao eucalipto diminui em espaçamentos inferiores a 14 m (ZAMBRANO, 2013; FRANCHINI et al., 2014), e o plantio em nível reduz as perdas de solo e água (SILVA et al., 2011). O eucalipto reduz a umidade no solo em sistemas com maior densidade de árvores (BEHLING NETO et al., 2012), em distâncias inferiores a $20 \mathrm{~m}$ dos eucaliptos intercalado com milho (CHANIE et al., 2013). Já em sistema silvipastoril, a umidade diminui em camadas mais profundas em Latossolo, próximas às linhas de plantio de árvores nativas (PEZZOPANE et al., 2015).
Na região do Noroeste do Paraná, visualmente tem sido observado que as pastagens intercalares às fileiras de eucalipto em sistema silvipastoril apresentam maior vigor do que em monocultivos, seja no inverno ou durante estiagens no verão. Esta observação empírica pode estar relacionada a efeitos do componente arbóreo na umidade no solo, pois em trabalhos anteriores realizados na mesma área foi observado redução da velocidade do vento em sistema silvipastoril (SOUZA et al., 2010; BALISCEI et al., 2012), que é um dos fatores responsáveis pela perda de água por evaporação. Se o sistema silvipastoril melhora o microclima em relação ao monocultivo de pastagem, proporcionando sombreamento e conforto térmico aos animais com maior tempo de pastejo nas horas de maior carga térmica radiante (SOUZA et al., 2010) e menor velocidade do vento (SOUZA et al., 2010; BALISCEI et al., 2012), então proporcionaria maior umidade no solo em sistema silvipastoril do que em monocultivo de pastagem (BERNARDINO; GARCIA, 2009).

A hipótese deste trabalho é que o sistema silvipastoril não diminui a umidade e não compromete água disponível na camada superficial no solo para a pastagem entre as fileiras duplas de eucalipto em relação ao sistema monocultivo de pastagem. O objetivo deste trabalho foi avaliar a umidade e a água disponível em sistema silvipastoril e monocultivo de pastagem em diferentes estações do ano, distância dos troncos de eucaliptos ou dos terraços a $1 \mathrm{~m}$ de profundidade em um Latossolo Vermelho Distrófico típico.

\section{Material e Métodos}

\section{Caracterização dos sistemas monocultivo de pastagem e silvipastoril}

O trabalho foi realizado na fazenda Santa Rita, adjacente a rodovia PR 557 e a $1 \mathrm{~km}$ do Distrito de Cristo Rei do município de Paranavaí, no noroeste do Paraná (22ㅇ 44' latitude sul e 52으 28', longitude oeste e altitude de $453 \mathrm{~m}$ ), pertencente à bacia do rio Paranapanema. Este trabalho que compara dois sistemas 
(monocultivo de pastagem e silvipastoril) vem sendo desenvolvido desde dezembro de 2009, com avaliações de microclima e comportamento de bovinos de corte (BALISCEI et al., 2012; BALISCEI et al., 2013).

O clima, subtropical úmido mesotérmico segundo classificação de Köppen, é do tipo Cfa, caracterizado por apresentar verões quentes e concentração das chuvas nos meses de verão, sem estação seca definida (CAVIGLIONE et al., 2000), e o solo é um Latossolo Vermelho Distrófico típico (ZAPAROLI; GASPARETTO, 2010; SANTOS et al., 2013), textura franco-argilo- arenosa, A moderado, com textura areia-franca (Tabela 1), em relevo plano a suave-ondulado.

Em julho de 2008, em uma área de 12 ha, realizaram-se a reforma dos terraços em nível espaçados em 20 m, que consistiu da distribuição e incorporação de calcário com grade aradora e niveladora e plantio de manivas de mandioca (Manihot esculenta) com adubação mineral. Esta área foi dividida em dois sistemas com 6 ha cada um: a) sistema monocultivo de pastagem e b) sistema silvipastoril.

Tabela 1. Atributos físicos e químicos dos horizontes de Latossolo Vermelho Distrófico típico, em sistemas monocultivo de e silvipastoril.

\begin{tabular}{|c|c|c|c|c|c|c|}
\hline $\begin{array}{c}\text { Camada } \\
(\mathrm{m})\end{array}$ & Argila & $\begin{array}{c}\text { Silte } \\
\left(\mathrm{g} \mathrm{kg}^{-1}\right)\end{array}$ & Areia & Classe textural $^{1}$ & Horizonte & $\begin{array}{l}V \\
(\%)\end{array}$ \\
\hline \multicolumn{7}{|c|}{ Sistema monocultivo de pastagem } \\
\hline $0,0-0,2$ & 118 & 81 & 801 & areia-franca & A & 40 \\
\hline $0,2-0,4$ & 184 & 27 & 789 & franco-arenosa & Bw1 & 51 \\
\hline $0,4-2,0$ & 259 & 27 & 714 & franco-argilo-arenosa & Bw2 & 28 \\
\hline \multicolumn{7}{|c|}{ Sistema silvipastoril } \\
\hline $0,0-0,2$ & 135 & 45 & 820 & Areia-franca & A & 39 \\
\hline $0,2-0,4$ & 160 & 128 & 712 & franco-arenosa & Bw1 & 26 \\
\hline $0,4-2,0$ & 221 & 76 & 703 & franco-argilo-arenosa & Bw2 & 27 \\
\hline
\end{tabular}

${ }^{1}$ Santos et al. (2005).

No sistema silvipastoril, após o plantio de mandioca, mudas de eucalipto foram plantadas em fileiras duplas espaçadas em $3 \mathrm{~m}$ e $2 \mathrm{~m}$ dentro das fileiras, a jusante dos terraços de base média espaçados em $20 \mathrm{~m}:(2 \times 3)+20$, totalizando 472 árvores ha ${ }^{-1}$. Em janeiro de 2010, após a colheita da mandioca, foram plantadas mudas de grama-estrela roxa (Cynodon nlemfuensis) para o estabelecimento da pastagem nos dois sistemas e concluindo a recuperação de pastagem preconizada por Marun e Mella (1997), para a região Noroeste do Paraná.

O manejo da grama-estrela roxa foi realizado com pastejo contínuo e taxa de lotação de 12 novilhos de bovinos em cada um dos sistemas (BALISCEl et al., 2012). Houve maior produção de matéria seca da grama-estrela roxa no verão do que no inverno, independentemente dos dois sistemas (BALISCEl et al., 2012).

\section{Amostragem e umidade no solo}

Quando os eucaliptos tinham de 24 meses de idade e $8 \mathrm{~m}$ de altura (BALISCEl et al., 2012) até 36 meses de idade, correspondendo ao período de maior demanda hídrica, quando ocorre a maior produção de biomassa foliar (REIS et al., 1985), avaliou-se o conteúdo de água no solo $(\theta)$ nos dois sistemas, em 8 dias, pelo método gravimétrico, que consistiu da coleta de amostras deformadas de solo em duas datas em cada uma das quatro estações do ano: inverno $(21 / 07 / 2010$ e 24/07/2010), primavera (02/11/2010 e 14/11/2010), verão (28/01/2011 e $15 / 02 / 2011)$ e verão/outono (21/03/2011 e 26/03/2011).

As coletas das amostras deformadas de solo foram realizadas utilizando um trado de $1 \mathrm{~m}$ de altura e copo amostrador $(0,3 \mathrm{~m}$ de altura $\mathrm{x}$ $0,075 \mathrm{~m}$ de diâmetro) e serra na extremidade inferior para possibilitar as coletas de amostras de solo em diferentes umidades. As amostras de solo foram coletadas as distâncias de $2,5,5$ e 10 $\mathrm{m}$, correspondendo as proporções, respectivamente, de $1 / 8,1 / 4$ e $1 / 2$ entre os troncos dos eucaliptos espaçados em $20 \mathrm{~m}$ no sistema silvipastoril, a jusante dos terraços no sistema monocultivo de pastagem, perpendicularmente ao declive do terreno (Figura 
1), nas profundidades de $0-0,2,0,2-0,4,0,4-0,6$, 0,6-0,8 e 0,8-1,0 m, correspondentes a três horizontes do Latossolo Vermelho Distrófico típico (Tabela 1). As coletas das amostras de solo foram realizadas em três repetições para cada uma das oito datas, repetindo-se os procedimentos apresentados na Figura 1, resultando na coleta de 720 amostras de solo. As amostras de solo foram acondicionadas em frascos de vidro e tampa plástica, transportadas em caixas de isopor para obter a massa úmida. Posteriormente, os vidros com as amostras de solo foram mantidos em estufa a 105 으 por $48 \mathrm{~h}$ para determinar $\theta$ (DONAGEMA et al., 2011).

Figura 1. Croqui com os pontos de amostragem (o), estações e datas das coletas de amostras de solo em relação aos terraços em nível com eucalipto $(\mathbf{\Delta})$ em sistema silvipastoril $(A)$ e monocultivo de pastagem (B).
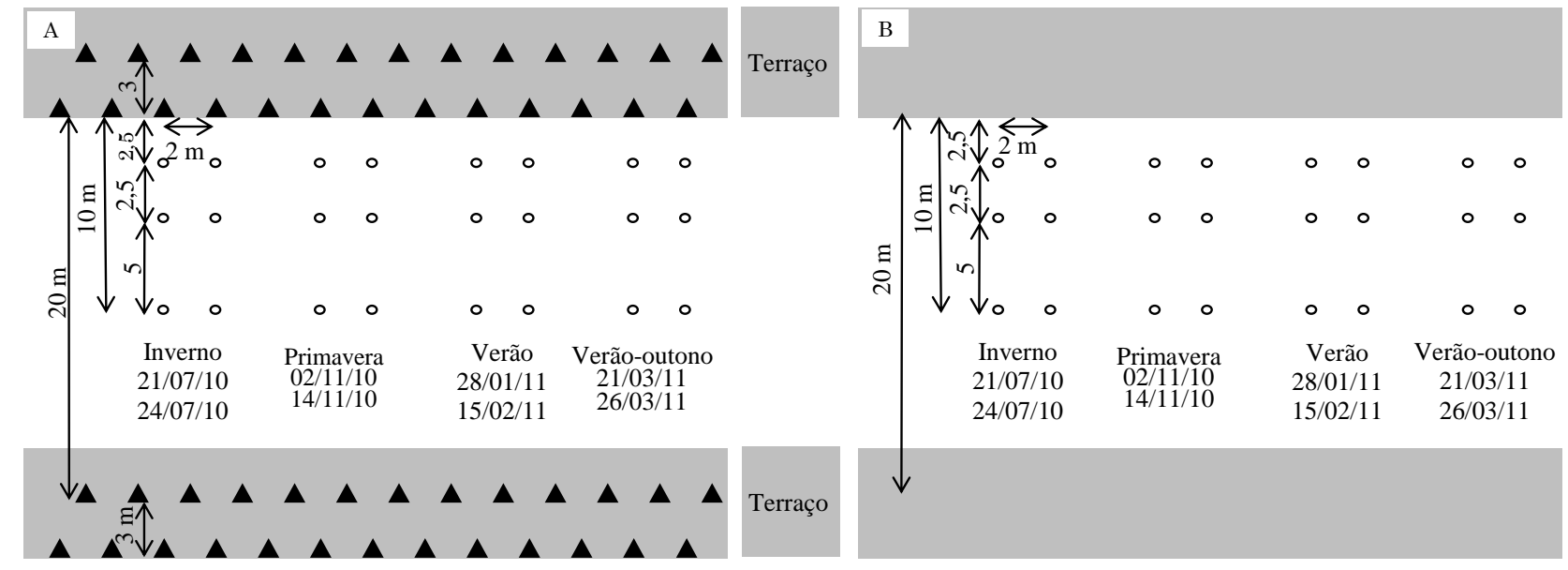

Em julho de 2010, amostras indeformadas de solo coletadas em triplicatas nos dois sistemas, nas três distâncias e nas cinco profundidades foram utilizadas para obter a água em mesa de tensão a $8 \mathrm{kPa}$, e após o secamento natural das amostras de solo, alíquotas de $2 \mathrm{~g}$ de solo foram colocadas dentro de cápsulas do medidor de potencial de água para obter potenciais matriciais no solo abaixo e acima da tensão de 1500 kPa (DECAGON DEVICES, 2007; FIDALSKI et al., 2013). Em seguida, essas amostras de solo das cápsulas e o solo restante das determinações da mesa de tensão foram mantidos em estufa a $105^{\circ} \mathrm{C}$ por $48 \mathrm{~h}$, para obter $\theta$ correspondente a capacidade de campo e ponto de murcha permanente, respectivamente, 8 e $1500 \mathrm{kPa}$.

\section{Inventário florestal}

O inventário florestal foi realizado tipo censo em junho de 2011 (ENCINAS et al., 2002). A circunferência e a altura do peito a $1,30 \mathrm{~m}$ do solo foram obtidas com uma trena métrica, e a altura com um Hipsómetro "Carl Leiss".

\section{Análise dos resultados de umidade no solo}

Os valores de $\theta$ dos dois sistemas foram comparados pelo teste $t$, na mesma camada e distância, considerando-se as duas datas em cada uma das quatro estações avaliadas.

\section{Resultados e Discussão \\ Precipitações pluviais}

Não houve precipitação no inverno (21/07/2010 a 24/07/2010), na primavera ocorreram $43 \mathrm{~mm}(02 / 11 / 2010$ a 14/11/2010), $211 \mathrm{~mm}$ no verão (28/01/2011 a 15/02/2011) e $10 \mathrm{~mm}$ no verão/outono (21/03/2011 a $26 / 03 / 2011$ ), antecedidos, respectivamente, por 27, 100, 186 e $10 \mathrm{~mm}$ (Figura 2). Considerandose as precipitações das Cartas Climáticas para a Fazenda Santa Rita em Paranavaí, no noroeste do Paraná (CAVIGLIONE et al., 2000), houve três estações com estiagem (inverno, primavera e verão-outono, respectivamente, com amplitudes de 25-50, 100-125 e 100-125 mm) e uma estação chuvosa no verão com amplitude $125-175 \mathrm{~mm}$. 
Figura 2. Precipitação pluvial durante inverno (1), primavera (2), verão (3) e verão/outono (4), entre julho/2010 a março/2011, na Fazenda Santa Rita, Paranavaí, no noroeste do Paraná.

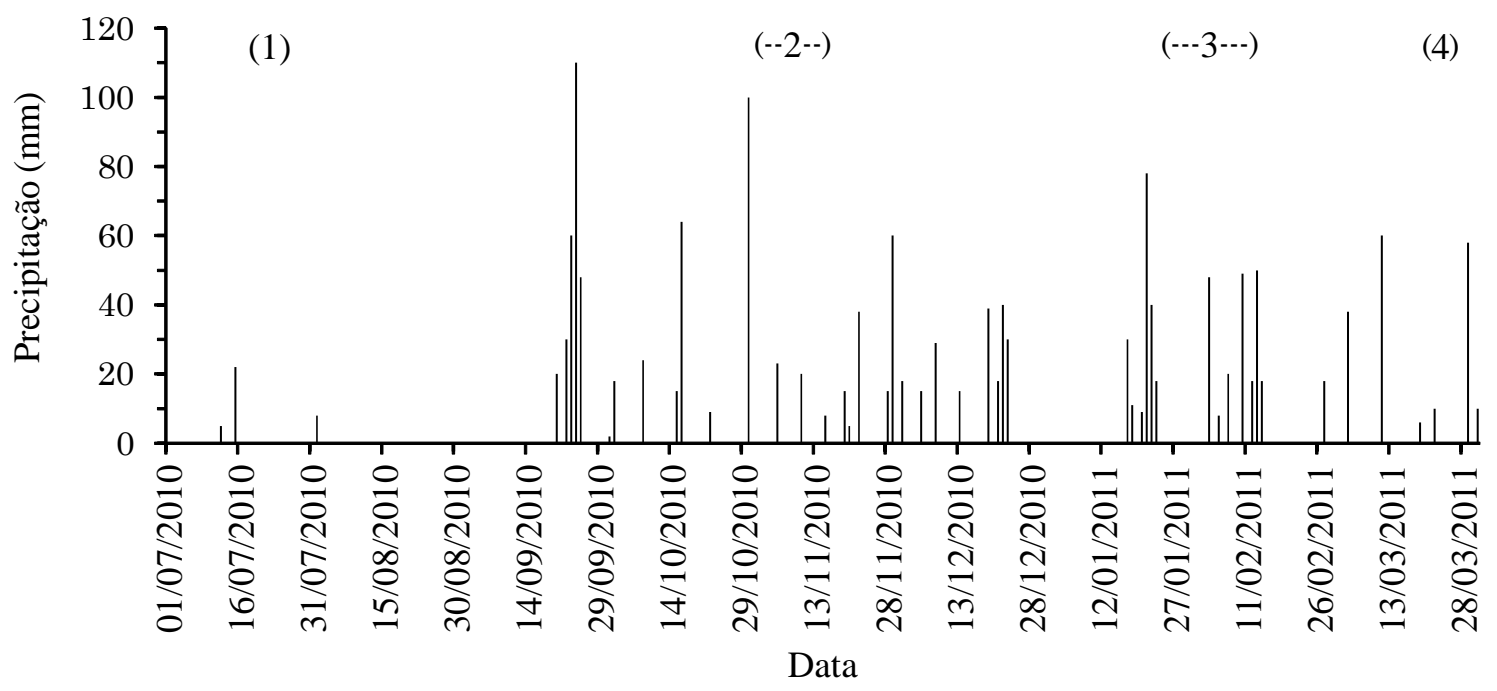

\section{Umidade no solo}

O sistema silvipastoril aumentou $\theta$ a $10 \mathrm{~m}$ na camada de 0-0,2 $\mathrm{m}$, no horizonte $A$ do Latossolo Vermelho Distrófivo típico, para as quatro estações em 2010 e 2011 (Figura 3A; Tabela 1), corroborando aos resultados obtidos por Soares et al. (2009), os quais verificaram que a 4,5 e 7,5 $\mathrm{m}$ da linha de Pinus taeda o $\theta$ na camada de 0-0,2 $\mathrm{m}$ foi maior que no sistema monocultivo de pastagem. 0 componente arbóreo não comprometeu o $\theta$ a 5 e $10 \mathrm{~m}$ na camada de 0,2-0,4 $\mathrm{m}$ do horizonte Bw2 (Figura
3B), à exceção do inverno (21/07/2010 e $24 / 07 / 2010$ ), quando houve menor $\theta$ a $2,5 \mathrm{~m}$ do tronco de eucalipto no sistema silvipastoril e a 10 $\mathrm{m}$ no sistema monocultivo de pastagem. Estes resultados estão associados a menor produtividade de grama-estrela roxa independentemente dos sistemas avaliados (BALISCEI et al., 2012). 
Figura 3. Umidade gravimétrica $(\theta)$ no solo em quatros estações a 2,5, 5 e $10 \mathrm{~m}$ do tronco de eucalipto e abaixo do terraço, para os sistemas silvipastoril $(\Delta, \mathrm{O}$ e $\square$, respectivamente) e monocultivo de pastagem ( $\boldsymbol{\Lambda}$,

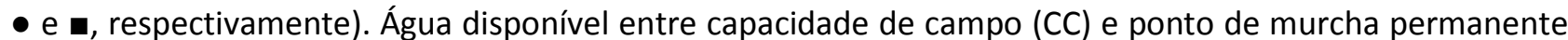
(PMP), na camada de 0-0,2 m do horizonte $A(A), 0,2-0,4 \mathrm{~m}$ do horizonte Bw1 (B) e 0,4-1,0 m do horizonte Bw2 (C). ${ }^{* * *},{ }^{* *}, * e^{\text {ns }}$, respectivamente, $\mathrm{P}<0,01, \mathrm{P}<0,05, \mathrm{P}<0,10$ e não significativo $(\mathrm{P}>0,10)$ pelo teste $\mathrm{t}$ entre as duas datas de cada estação.
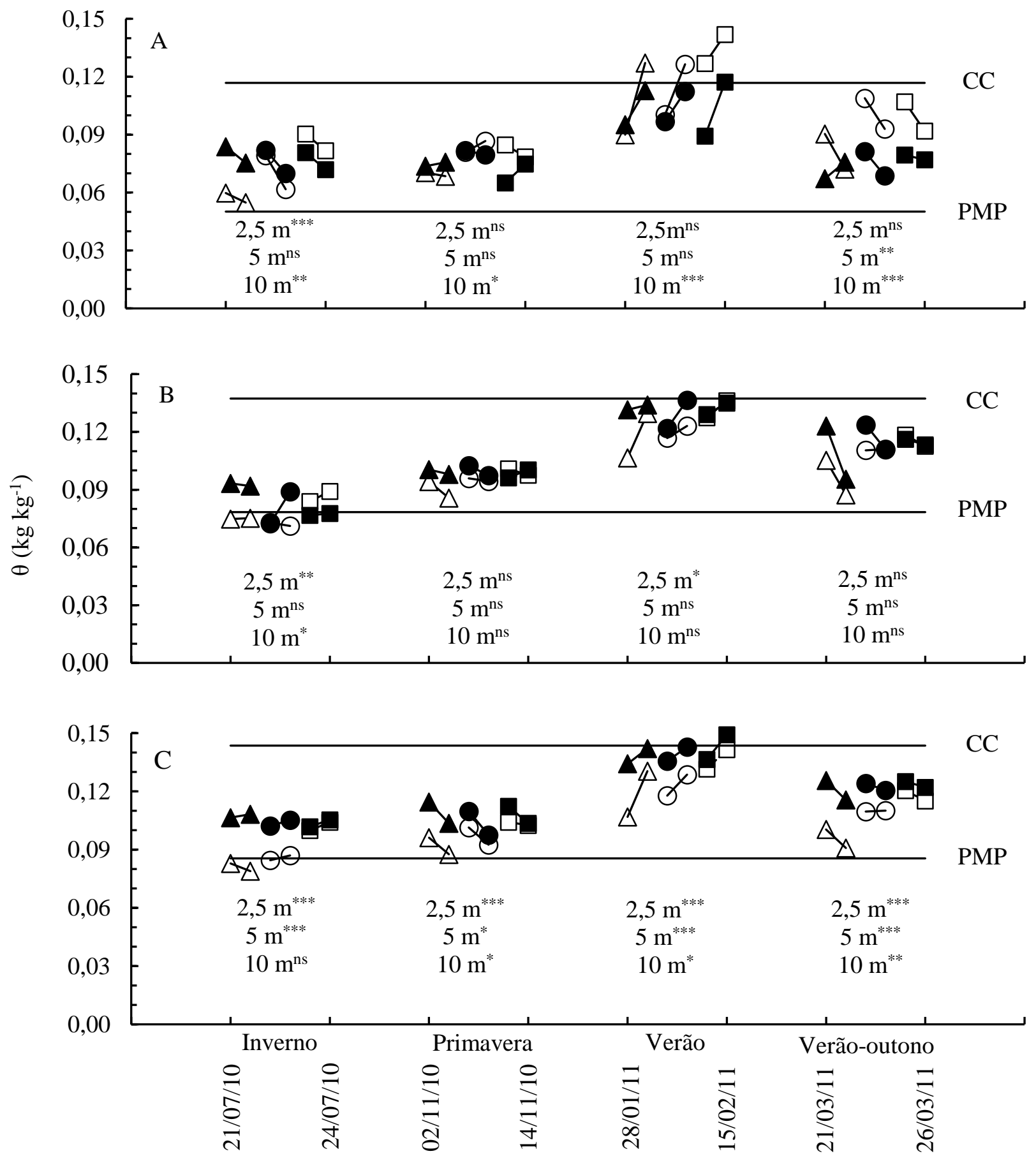

Data (dia, mês e ano)

O sistema silvipastoril reduziu o $\theta$ em todo o horizonte Bw2 entre as fileiras duplas de eucalipto, nas quatro estações avaliadas, à exceção no centro da grama-estrela roxa no inverno a $10 \mathrm{~m}$ do tronco de eucalipto no sistema silvipastoril e dos terraços no sistema em monocultivo de pastagem (Figura $3 \mathrm{C}$ ). $\mathrm{O}$ sistema silvipastoril foi dependente de $\theta$ somente do 
horizonte Bw2 a 0,4-1,0 m de profundidade com maior teor de argila (Tabela 1). Resultados semelhantes foram obtidos por Pezzopane et al. (2015), que constataram menor $\theta$ em camadas mais profundas do solo, próximo às linhas de plantio das árvores nativas em sistema silvipastoril, sendo o Eucalyptus grandis dependente de $\theta$ da profundidade de 0,45-2,55 $\mathrm{m}$ avaliados aos 32-38 meses de idade em Latossolo Vermelho-Amarelo álico textura francoargilo-arenosa (LEITE, 1999).

Os valores médios de $\theta$ estiveram dentro dos limites de água disponível, entre a capacidade de campo e ponto de murcha permanente (Figura $3 A, B, C$ ), à exceção do excesso de $\theta$ no verão a $10 \mathrm{~m}$ no horizonte $A$ no sistema silvipastoril (Figura $3 \mathrm{~A}$ ); e limitante no inverno $\operatorname{com} \theta$ abaixo do ponto de murcha permanente no sistema monocultivo de pastagem a $10 \mathrm{~m}$ no horizonte Bw1 e a 2,5 $\mathrm{m}$ no horizonte Bw2 no sistema silvipastoril e monocultivo de pastagem (Figuras 3B,C). Estes resultados denotam que o sistema monocultivo de pastagem apresentou mais riscos de deficiência hídrica do que o sistema silvipastoril neste solo, enquanto Leite (1999) não verificaram valores de $\theta$ gravimétrico fora dos limites da água disponível no solo, para monocultivo de eucalipto em Latossolo Vermelho-Amarelo álico textura franco-argilo-arenosa.

A maior limitação hídrica próximo aos eucaliptos dos horizontes com textura francoargilo-arenosa (Figura 3C), se deve a maior concentração de raízes de eucalipto (WITSCHORECK et al., 2003), que contribuem para o secamento do solo em razão da maior extração de água para atender a demanda hídrica das plantas, nas camadas mais profundas. $O$ menor $\theta$ sob as copas dos eucaliptos se deve também à interceptação da água das precipitações pelas folhas dos eucaliptos (SARI et al., 2016).

O cultivo de eucalipto em renques em sistema silvipastoril diminuiu o $\theta$ nas camadas de 0,4-1,0 m, durante o período de máxima biomassa foliar, dos 24 aos 36 meses (REIS et al., 1985; LEITE, 1999; CALDER, 2007; SANTANA et al., 2008). A redução do $\theta$ pelo eucalipto e o secamento do solo também foi observado por Rodrigues et al. (2012), justificado pela elevada demanda hídrica das plantas, que segundo Leite (1999) e Behling Neto et al. (2012) faz com que seja necessária uma adequação da população de eucaliptos, seja em monocultivo de eucalipto ou sistema silvipastoril.

O eucalipto pode causar baixo rendimento de culturas consorciadas, como no caso do consórcio entre milho e eucalipto (MACEDO et al., 2006; CHANIE et al., 2013) e da pastagem em integração lavoura-pecuáriafloresta com fileiras duplas de eucalipto espaçadas em $14 \mathrm{~m}$ (FRANCHINI et al., 2014). Contudo, a produção de pastagem e a taxa de lotação de bovinos foram similares em sistemas silvipastoril e monocultivo de pastagem na área do presente trabalho com benefícios do microclima para os animais (BALISCEl et al., 2012; BALISCEl et al., 2013).

O sistema silvipastoril avaliado apresentou diferenças de $\theta$ associado à textura dos horizontes do Latossolo Vermelho Distrófico típico: maior $\theta$ no horizonte $A$ moderado, indiferença no horizonte Bw1 e menor $\theta$ no horizonte Bw2 (Figura 3; Tabela 1). A constatação da influência dos sistemas no $\theta$ entre os horizontes do perfil do Latossolo Vermelho Distrófico típico (Figura $3 A, B, C$ ), e de que o sistema silvipastoril tem mais $\theta$ na camada superficial arenosa, vem a corroborar as iniciativas de implantação deste sistema na região do noroeste do Paraná (SOUZA et al., 2010; BALISCEl et al., 2012; ZAMBRANO, 2013), com menores riscos de perdas de solo pela erosão (OLIVEIRA et al., 2013), atendendo a aptidão agrícola do Latossolo Vermelho Distrófico típico textura franco-argilo-arenosa.

\section{Inventário florestal}

No final das avaliações do $\theta$, aos 36 meses do plantio das mudas de eucalipto, as árvores de eucalipto tinham altura média de 11 $\mathrm{m}$ e produção de $48 \mathrm{~m}^{3}$ de madeira (Tabela 2 ). Esta produção de madeira pode ser considerada adequada em relação às produções obtidas por Fick (2011) e Franchini et al. (2014) em condições edafoclimáticas similares. Tais resultados permitiram confirmar que a opção de implantação de sistema silvipastoril a partir da reforma de pastagem degradada com o cultivo de mandioca e eucalipto constitui uma opção para Latossolo Vermelho Distrófico típico do arenito para o noroeste do Paraná. Para viabilizar a reforma de pastagens degradadas com o cultivo de mandioca, alguns agropecuaristas estão aceitando reduzir o custo de arrendamento proporcional a área de cultivo de mandioca para a implantação de sistema silvipastoril com 
eucalipto, excluindo a área que seria ocupada com eucalipto, no presente trabalho $(2 \times 3)+20$ teria que ser reduzido em $8 \%$.

Tabela 2. Inventário florestal de Eucaliptus grandis, aos 36 meses após plantio.

\begin{tabular}{|c|c|c|c|c|c|c|c|}
\hline \multicolumn{2}{|c|}{ Densidade de plantas } & \multirow[t]{2}{*}{ Falha } & \multirow{2}{*}{$\begin{array}{l}\text { Altura } \\
\text { média }\end{array}$} & \multirow{2}{*}{$\begin{array}{l}\text { Diâmetro } \\
\text { médio }\end{array}$} & \multicolumn{2}{|c|}{ Volume de madeira } & \multirow{2}{*}{$\begin{array}{c}\text { Incremento médio } \\
\text { anual }\end{array}$} \\
\hline Julho/2008 & Junho/2011 & & & & árvore & & \\
\hline \multicolumn{2}{|c|}{$\left(\right.$ plantas ha $\left.^{-1}\right)$} & (\%) & & m) & $\left(\mathrm{m}^{3}\right)$ & $\left(\mathrm{m}^{3} \mathrm{ha}^{-1}\right)$ & $\left(\mathrm{m}^{3} \mathrm{ha}^{-1} \mathrm{ano}^{-1}\right)$ \\
\hline 472 & 395 & 16 & 11,02 & 0,171628 & 0,122441 & 48,36 & 16,12 \\
\hline
\end{tabular}

O cultivo de eucalipto apresenta equilíbrio entre evapotranspiração e precipitação em anos em que a precipitação é próxima à média anual (ALMEIDA; SOARES, 2003). Nas áreas dos dois sistemas avaliados neste trabalho, a evapotranspiração e a precipitação médias anuais correspondem a $1400 \mathrm{~mm}$ (CAVIGLIONI et al., 2000), similares aos índices obtidos por Almeida e Soares (2003). Por essas similaridades, o $\theta$ foi dependente do manejo diferenciado entre os sistemas monocultivo de pastagem e silvipastoril (Figura 3). Neste contexto, Fernández et al. (2008) constataram que as árvores em sistema silvipastoril consomem menos água do que o monocultivo de eucalipto, os quais consideram que o consórcio de eucalipto e pastagem melhoram a utilização do $\theta$ em sistema silvipastoril (BERNARDINO; GARCIA, 2009), vindo a confirmar a hipótese de que o sistema silvipastoril em Latossolo Vermelho Distrófico típico não compromete o $\theta$ na camada superficial do solo para a pastagem entre as fileiras duplas de eucalipto espaçadas em $20 \mathrm{~m}$ a $0,4 \mathrm{~m}$ de profundidade, correspondente aos horizontes $\mathrm{A} \mathrm{e}$ Bw1.

A contribuição deste trabalho ao confirmar as observações empíricas de que a pastagem grama-estrela roxa entre as fileiras duplas de eucalipto em sistema silvipastoril tem aspecto visual mais esverdeado devido o maior $\theta$ e menor velocidade do vento, devido a maior concentração de nitrogênio nas folhas das gramíneas, proporcionada pela liteira, que se acumula em sistema silvipastoril (BERNARDINO; GARCIA, 2009). Portanto, os resultados do presente trabalho permitem recomendar este sistema conservacionista implantado durante a reforma de pastagem aos agropecuaristas em solos similares dos estados do Paraná, Mato Grosso do Sul e São Paulo (SALLUN et al., 2007; SALLUN et al., 2008), com vantagens microclimáticas para os bovinos e a produção de madeira de eucalipto.

\section{Conclusões}

O sistema silvipastoril comparado ao monocultivo de pastagem diminuiu o $\theta$ no horizonte Bw2.

O $\theta$ esteve dentro dos limites da água disponível nos horizontes A e Bw1 para a gramaestrela roxa entre as fileiras duplas de eucalipto no sistema silvipastoril durante as estações do ano.

O sistema silvipastoril $(2 \times 3)+20$ com Eucalyptus grandis não compromete o $\theta$ para a grama-estrela roxa a 0-0,4 $\mathrm{m}$ de profundidade em Latossolo Vermelho Distrófico típico.

\section{Referências}

ALMEIDA, A. C. de.; SOARES J. V. Comparação entre uso de água em plantações de Eucalyptus grandis e floresta ombrófila densa (Mata Atlântica) na costa leste do Brasil. Revista Árvore, v. 27, n. 2, p. 159-170, 2003.

https://doi.org/10.1590/S0100$\underline{67622003000200006}$

BALISCEI, M. A.; SOUZA, W.; BARBOSA, O. R.; CECATO, U.; KRUTZMANN, A.; QUEIROZ, E. O. Behavior of beef cattle and the microclimate with and without shade. Acta Scientiarum Animal Sciences, v. 34, n. 4, p. 409-415, 2012. https://doi.org/10.4025/actascianimsci.v34i4.150 $\underline{55}$

BALISCEI, M. A.; BARBOSA, O. R.; SOUZA, W.; COSTA, M. A. T.; KRUTZMANN, A.; QUEIROZ E. D. Microclimate without shade and silvopastoral system during summer and winter. Acta Scientiarum Animal Sciences, v. 35, n. 1, p. 4956, 2013. 
https://doi.org/10.4025/actascianimsci.v35i1.151 $\underline{55}$

BEHLING NETO, A.; ALMEIDA, R. G. de; ABREU, J. G. de; MACEDO, C. M. M.; BUNGENSTAB, D. J.; GAMARRA, E. L.; PASCULLI, B. Soil moisture in different cropping systems. In: INTERNATIONAL SYMPOSIUM ON INTEGRATED CROP-LIVESTOCK SYSTEMS, 2., 2012, Porto Alegre. Anais [...]. Porto Alegre: INRA, 2012. 3 p. Disponível em: https://www.researchgate.net/publication/2672 11731_Soil_moisture_in_different_cropping_syst ems. Acesso em: 26 mar. 2016.

BERNARDINO, F. S.; GARCIA, R. Sistemas silvipastoris. Pesquisa Florestal Brasileira, edição especial, n. 60, p. 77-87, 2009.

CALDER, I. R. Forests and water: Ensuring forest benefits outweigh water. Forest Ecology and Management, v. 251, n. 1/2, p. 110-120, 2007. https://doi.org/10.1016/i.foreco.2007.06.015

CAVIGLIONE, J. H.; KILHL, L. R. B.; CARAMORI, P. H.; OLIVEIRA, D.; PUGSLEY, L. Cartas climáticas do Paraná. Londrina: lapar, 2000. 1 CD-ROM.

CHANIE, T.; COLLICK, A. S.; ADGO, E.; LEHMANN, C. J.; STEENHUIS, T. S. Eco-hydrological impacts of Eucalyptus in the semi humid Ethiopian Highlands: the lake plain. Journal of Hydrology and Hydromechanics, v. 61, n. 1, p. 21-29, 2013. https://doi.org/10.2478/johh-2013-0004

COLODETTE, J. L.; GOMES, C. M.; GOMES, F. J.; CABRAL, C. P. The brazilian wood biomass supply and utilization focusing on eucalypt. Chemical and Biological Technologies in Agriculture, v. 1, n. 25, p. 1-8, 2014.

https://doi.org/10.1186/s40538-014-0025-x

DECAGON DEVICES. WP4 dewpoint potentiameter for models wp4 and wp4-t: operator's manual: version 5. Pullman: Decagon, 2007. $78 \mathrm{p}$.

DONAGEMA, G. K.; CAMPOS, D. V. B. de; CALDERANO, S. B.; TEIXEIRA, W. G.; VIANA, J. H. M. Manual de métodos de análise de solo. 2. ed. Rio de Janeiro: Embrapa Solos, 2011. 230 p. (Série Embrapa Solos. Documentos, 132).

ENCINAS, J. I.; SILVA, G. F. da; KISHI, I. T. Variáveis dendrométricas. Brasília, DF: Universidade de
Brasília, 2002. 102 p. (Série Comunicações Técnicas Florestais, 4).

FERNÁNDEZ, M. E.; GYENGE, J.; LICATA, J.; SCHLICHTER, T.; BOND, B. J. Belowground interactions for water between trees and grasses in a temperate semiarid agroforestry system. Agroforestry Systems, v. 74, n. 2, p. 185-197, 2008. https://doi.org/10.1007/s10457-008-9119$\underline{4}$

FEY, R.; MALAVASI, U. C.; MALAVASI, M. M. Silvopastoral system: a review regarding the family agriculture. Revista de Agricultura Neotropical, v. 2, n. 2, p. 26-41, 2015. https://doi.org/10.32404/rean.v2i2.265

FICK, T. A. Amostragem para inventário florestal em sistemas silvipastoris. Revista Árvore, v. 35, n. 5, p. 1033-1038, 2011.

https://doi.org/10.1590/S0100-

$\underline{67622011000600009}$

FIDALSKI, J.; TORMENA, C. A.; ALVES, S. J.; AULER, P. A. M. Influência das frações de areia na retenção e disponibilidade de água em solos das formações Caiuá e Paranavaí. Revista Brasileira de Ciência do Solo, v. 37, n. 3, p. 613-621, 2013. https://doi.org/10.1590/s0100-

$\underline{06832013000300007}$

FRANCHINI, J. C.; FRANCHINI, J. C.; BALBINOT JUNIOR, A. A.; SICHIERI, F. R.; DEBIASI, H.; CONTE, $O$. Yield of soybean, pasture and wood in integrated crop-livestock-forestsystem in Northwestern Paraná state, Brazil. Revista Ciência Agronômica, v. 45, n. 5, p. 1006-1013, $2014 . \quad$ https://doi.org/10.1590/S1806$\underline{66902014000500016}$

LEITE, F. P. Relações hídricas em povoamento de eucalipto com diferentes densidades populacionais. Revista Brasileira de Ciência do Solo, v. 23, n. 1, p. 9-16, 1999.

https://doi.org/10.1590/S0100-

$\underline{06831999000100002}$

MACEDO, R. L. G.; BEZERRA, R. G.; VENTURIN, N.; VALE, R. S.; OLIVEIRA, T. K. Desempenho silvicultural de clones de eucalipto e características agronômicas de milho cultivados em sistema silviagrícola. Revista Árvore, v. 30, n. 5, p. 701-709, 2006. 
https://doi.org/10.1590/S0100-

67622006000500003

MARUN, F.; MELLA, S. C. Recuperação de pastagens pela sucessão de culturas anuais e bianuais: um estudo no noroeste do Paraná. Londrina: IAPAR, 1997. 24 p. (IAPAR. Boletim técnico, 52).

NEPOMUCENO, A. N.; SILVA, I. C. Caracterização de sistemas silvipastoris da Região Noroeste do Estado do Paraná. Floresta, v. 39, n. 2, p. 279-87, 2009. https://doi.org/10.5380/rf.v39i2.14556

OLIVEIRA, A. H.; SILVA, M. L. N.; CURI, N.; AVANZI, J. C.; KLINKE NETO, G.; ARAÚJO, E. F. Water erosion in soils under eucalyptus forest as affected by development stages and management systems. Ciência e Agrotecnologia, v. 37, n. 2, p. 159-169, 2013.

https://doi.org/10.1590/S1413-

$\underline{70542013000200007}$

PEZZOPANE, J. R. M.; BOSI, C.; FRANCESCHI, N. P. M. S.; CRUZ, P. G. da; PARMEJIANI, R. S. Microclimate and soil moisture in a silvopastoral system in southeastern Brazil. Bragantia, Campinas, v. 74, n. 1, p. 110-119, 2015.

https://doi.org/10.1590/1678-4499.0334

REIS, M. G. F.; KIMMINS, J. P.; REZENDE, G. C. de; BARROS, N. F. de. Acúmulo de biomassa em uma sequência de idade de Eucalyptus grandis plantado no cerrado em duas áreas com diferentes produtividades. Revista Árvore, Viçosa, MG, v. 9, n. 2, p. 149-162, 1985.

RODRIGUES, V. A.; FENNER, P. T.; SANSIGOLO, C. A.; MORAES, M. H. Estimativa da água no solo em floresta de Eucalyptus grandis. Irriga, Botucatu, v. 17, n. 4, p. 523-533, 2012.

https://doi.org/10.15809/irriga.2012v17n4p523

SALLUN, A. E. M.; SUGUIO, K.; STEVAUX, J. C. Proposição formal do Alogrupo Alto Rio Paraná (SP, PR e MS). Geologia Série Científica USP, São Paulo, v. 7, n. 2, p. 49-70, 2007.

https://doi.org/10.5327/Z1519-

874X2007000200004

SALLUN, A. E. M.; SUGUIO, K.; AZEVEDO SOBRINHO, J. M. Sedimentologia da aloformação Paranavaí, bacia hidrográfica do alto rio Paraná (SP, PR E MS). Revista Pesquisas em Geociências,
Porto Alegre, v. 35, n. 1, p. 85-107, 2008.

https://doi.org/10.22456/1807-9806.17897

SANTOS, H. G.; JACOMINE, P. K. T.; ANJOS, L. H. C.; OLIVEIRA, V. A.; OLIVEIRA, J. B.; COELHO, M. R.; LUMBRERAS, J. F.; CUNHA, T. J. F. Sistema brasileiro de classificação de solos. 3. ed. Brasília, DF: Embrapa, 2013. 353 p.

SANTOS, R. D. dos; LEMOS, R. C. de; SANTOS, H. G. dos; KER, J. C.; ANJOS, L. H. C. dos. Manual de descrição e coleta de solo no campo. 5. ed. Viçosa, MG: SBCS, 2005. 100 p.

SARI, V.; PAIVA, E. M. C. D. de; PAIVA, J. B. D. de. Interceptação da chuva em diferentes formações florestais na região sul do Brasil. Revista Brasileira de Recursos Hídricos, Porto Alegre, v. 21, n. 1, p. 65-79, 2016.

https://doi.org/10.21168/rbrh.v21n1.p65-79

SILVA, M. A. da; SILVA, M. L. N.; CURI, N., AVANZI, J. C.; LEITE, F. P. Sistemas de manejo em plantios florestais de eucalipto e perdas de solo e água na região do Vale do Rio Doce, MG. Ciência Florestal, Santa Maria, v. 21, n. 4, p. 765-776, 2011. https://doi.org/10.5902/198050984520

SOARES, A. B.; SARTOR, L. R.; ADAMI, P. F.; VARELLA, A. C.; FONSECA, L.; MEZZALIRA, J. C. Influência da luminosidade no comportamento de onze espécies forrageiras perenes de verão. Revista Brasileira de Zootecnia, Viçosa, MG, v. 38, n. 3, p. 443-451, 2009.

https://doi.org/10.1590/S1516$\underline{35982009000300007}$

SOUZA, W.; BARBOSA, O. R.; MARQUES, J. A.; GASPARINO, E.; CECATO, U.; BARBERO, L. M. Behavior of beef cattle in silvipastoral systems with eucalyptus. Revista Brasileira de Zootecnia, Viçosa, MG, v. 39, n. 3, p. 677-684, 2010.

https://doi.org/10.1590/S1516-

$\underline{35982010000300029}$

ZAMBRANO, J. C. H. Sistema de integração lavoura-pecuária-floresta: produção forrageira e desempenho de novilhos. 2013. 63 f. Dissertação (Mestrando em Ciência Animal) - Universidade Estadual de Londrina, 2013.

ZAPAROLI, F. C. M.; GASPARETTO, N. V. L. Distribuição de solos e sua relação com o relevo em uma vertente no município de Floraí-PR. 
Boletim de Geografia, Maringá, v. 28, n. 2, p. 49-63, 2010.

https://doi.org/10.4025/bolgeogr.v28i2.10372

WITSCHORECK, R.; SCHUMACHER, M. V.; CALDEIRA, M. V. W. Estimativa da biomassa e do comprimento de raízes finas em Eucalyptus urophylla S.T. Blake no município de Santa MariaRS. Revista Árvore, Viçosa, MG, v. 27, n. 2, p. 177-183, 2003. https://doi.org/10.1590/50100$\underline{67622003000200008}$ 